\title{
Association between social support and viral load in adults on highly active antiretroviral therapy - Witbank, South Africa
}

\begin{tabular}{|c|c|}
\hline \multicolumn{2}{|c|}{$\begin{array}{l}\text { Authors: } \\
\text { Temnewo M. Habte }{ }^{1} \text { (1) } \\
\text { Charles Bondo }^{1} \\
\text { Lushiku Nkombua }\end{array}$} \\
\hline \multicolumn{2}{|c|}{$\begin{array}{l}\text { Affiliations: } \\
{ }^{1} \text { Department of Family } \\
\text { Medicine, Faculty of } \\
\text { Health Sciences, University } \\
\text { of Pretoria, Pretoria, } \\
\text { South Africa }\end{array}$} \\
\hline \multicolumn{2}{|c|}{$\begin{array}{l}\text { Corresponding author: } \\
\text { Lushiku Nkombua, } \\
\text { lushiku.nkombua@up.ac.za }\end{array}$} \\
\hline \multicolumn{2}{|c|}{$\begin{array}{l}\text { Dates: } \\
\text { Received: } 06 \text { May } 2020 \\
\text { Accepted: } 19 \text { Sept. } 2020 \\
\text { Published: } 03 \text { Dec. } 2020\end{array}$} \\
\hline \multicolumn{2}{|c|}{$\begin{array}{l}\text { How to cite this article: } \\
\text { Habte TM, Bondo C, } \\
\text { Nkombua L. Association } \\
\text { between social support and } \\
\text { viral load in adults on highly } \\
\text { active antiretroviral } \\
\text { therapy - Witbank, South } \\
\text { Africa. S Afr Fam Pract. } \\
\text { 2020;62(1), a5139. https:// } \\
\text { doi.org/10.4102/safp. } \\
\text { v62i1.5139 }\end{array}$} \\
\hline \multicolumn{2}{|c|}{$\begin{array}{l}\text { Copyright: } \\
\text { ( ) 2020. The Authors. } \\
\text { Licensee: AOSIS. This wo } \\
\text { is licensed under the } \\
\text { Creative Commons } \\
\text { Attribution License. }\end{array}$} \\
\hline \multicolumn{2}{|c|}{ Read online: } \\
\hline 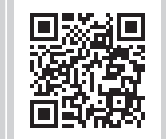 & $\begin{array}{l}\text { Scan this QR } \\
\text { code with your } \\
\text { smart phone or } \\
\text { mobile device } \\
\text { to read online. }\end{array}$ \\
\hline
\end{tabular}

Background: There are significant number of patients who are on highly active antiretroviral therapy (HAART) not virally suppressed, which is a huge clinical challenge. Social support as a non-pharmacological factor, which may influence the viral suppression, is less studied and has equivocal results. The aim of this study was to investigate the association between social support and viral load (VL) in adults on HAART.

Methods: This was an analytical cross-sectional study. Using a structured questionnaire, 380 adults ( $\geq 18$ years) on HAART for $\geq 6$ months were recruited between November 2018 and February 2019 from Witbank hospital and surrounding clinics. Multivariable logistic regression was carried out.

Results: The mean age of the participants was 40.5 years $($ s.d. $=10.3)$. The majority were females (73\%), at least high school educated (84\%), unemployed (57\%), single $(63 \%)$ and did not have comorbidity $(80 \%)$. The vast majority had moderate to high adherence $(84 \%)$ and moderate to good perceived social support (94\%). The viral suppression rate was $87 \%$. Both adherence $(p<0.001)$ and social support $(p=0.017)$ were significantly associated with VL. However, only adherence was predictive of viral suppression in multivariable analysis. Compared to poorly adherent, moderately $(\mathrm{OR}=2.8 ; 95 \% \mathrm{CI}=1.32-5.98)$ and highly $(\mathrm{OR}=5.3$; $95 \% \mathrm{CI}=2.41-11.81$ ) adherent participants were more likely to have suppressed VL.

Conclusion: Viral suppression rate was high. Self-reported adherence to HAART was highly predictive of viral suppression, which highlights the importance of assessing and addressing adherence issues at every contact with patients taking HAART. Good social support did not predict viral suppression.

Keywords: HIV; perceived social support; adherence; viral load; HAART.

\section{Introduction}

South Africa (SA) has the highest burden of the human immunodeficiency virus (HIV) epidemic in the world. According to the Joint United Nations Programme on HIV and AIDS (UNAIDS), 37.9 million people were living with HIV in 2018 globally. ${ }^{1}$ Eastern and Southern Africa is the most affected region with 20.6 million people living with HIV (PLHIV) in the same year, ${ }^{1}$ of which more than a third are from SA alone. ${ }^{1,2}$ Deaths related to acquired immunodeficiency syndrome (AIDS) were estimated to be 71000 in SA in 2018, which is a huge decline from 140000 deaths in 2010. ${ }^{1}$ This decline in AIDS-related deaths is largely attributed to the advances in highly active antiretroviral therapy (HAART).

Highly active antiretroviral therapy refers to the use of a combination of three or more antiretroviral drugs with the main goal of achieving viral suppression. ${ }^{3}$ In 2018, SA had about 4.7 million PLHIV on HAART, which is the largest in the world. ${ }^{1}$ However, there are a significant number of PLHIV who are not virally suppressed, and this is a huge challenge. In 2018, only $54 \%$ of PLHIV were virally suppressed in SA. ${ }^{1}$ Achieving the UNAIDS global target of $90-90-90$ ( $90 \%$ of PLHIV know their status, $90 \%$ of those diagnosed with HIV are on HAART and $90 \%$ of those on HAART to have viral suppression ${ }^{1,3,4}$ ) in the year 2020, especially the last 90 , has been an extremely difficult target. Identifying and addressing the non-pharmacological factors, which may influence the viral suppression, would be a vital adjunct to HAART.

Social support, being such a factor, is less studied and has equivocal results. In a Canadian study in the late 1990s and early 2000s, Burgoyne ${ }^{5}$ found that patients with better social support 
were more likely to have suppressed viral load (VL); however, although it was a prospective study over a 4-year period, the sample size was only 34 patients. A recent study done in Brazil showed patients with satisfactory social support had a significant reduction in VL. ${ }^{6}$ It was a cohort study with 1-year follow-up in which they analysed the effect of social support on quality of life, CD4 count and VL of PLHIV. They also found that in patients with unsatisfactory social support, there was no significant reduction in their VL.

Randomised control trials (RCTs) assessing different forms of support have shown mixed results. In a United States (US) study, adults with HIV VL $>1000$ copies/ $\mu \mathrm{L}$ and/or a CD4 count $<350$ cells $/ \mu \mathrm{L}$ were randomised to a community health worker (CHW) intervention group or control group. At 9 and 12 months, the intervention group had significantly lower VL than the control group. ${ }^{7}$ In a Vietnamese study, patients during initiation of HAART were randomised to a peer support intervention group or control group and were followed up for 2 years. After 2 years, peer support to improve adherence did not show any impact on the virologic and immunologic outcomes. ${ }^{8}$ The Vietnamese study was similar in the design and results (especially VL) to the study done in Cape Town, SA. In this SA study, patients during initiation of HAART were randomised to intervention (partial directly observed therapy [DOT] administered by community-based, patient-nominated treatment supporters) group or control (self-administered HAART) group and were followed up for 2 years. They found no significant differences in viral suppression between the two groups. ${ }^{9}$

A systematic review and meta-analysis of the literature, assessing the effect of directly observed therapy of HAART (DOT-HAART) on virologic, immunologic and adherence outcomes, has found that DOT-HAART has a significant effect on VL, CD4 count and adherence outcomes compared to control group; however, when analysis was done to RCTs only, DOT-HAART had no significant effect on VL. ${ }^{10}$ To add to the controversy, another systematic review and metaanalysis, assessing the effect of home-based interventions on virologic outcomes in adults receiving HAART in Africa, has found insufficient data to say there is a difference in viral suppression at 12 months in the home-based group compared to the standard care group. ${ }^{11}$

There are different forms of social support, as described by Streeter et al., ${ }^{12}$ one of which is perceived social support (the individual's perceived connections to others and his or her level of confidence that in times of need support will be available). Another one is enacted social support (received support), which is the specific actions provided by others as a gesture of support or assistance. The source of support can be formal (from professional services) or informal (from family and friends). ${ }^{12}$ Some of the aforementioned studies assessed perceived social support whilst others assessed what is considered as enacted social support provided by formal and informal sources of support. Different forms of social support have conflicting or different clinical outcomes on HIV VL. The evidence on the influence of social support on clinical outcome of adults on HAART is not clear cut. The primary aim of the current study is to investigate the association between perceived social support and VL amongst adults on HAART attending Witbank hospital and surrounding clinics in Emalahleni subdistrict, Mpumalanga, Republic of South Africa. Other factors (demographic, comorbidity and HAART adherence) that may influence the VL and have an effect on multivariable analysis were also explored.

\section{Methods Study design}

This was an analytical cross-sectional study.

\section{Participant selection}

The study was conducted at the wellness clinic in Witbank hospital, which is a provincial tertiary hospital, and six other surrounding primary healthcare clinics located in Emalahleni, Mpumalanga. The Wellness clinic is a specialised HIV clinic, accepting referrals of patients with multiple comorbidities and those with virologic failures. The target population was all adults who were on HAART for 6 months or more. Adults who were 18 years or older and had a VL result were included in the study. Those who did not have VL results but were due for their routine VL monitoring were also included (blood was taken for VL and results traced using a barcode). Those who did not have VL results in which results could not be traced and those who did not consent were excluded from the study. A consecutive sampling method was used. All adults who met the inclusion criteria during the study period between November 2018 and February 2019 were recruited by the researcher and a trained research assistant until the required sample size was met.

\section{Measurements}

A structured questionnaire was used to assess the following variables: the demographic data including a question on comorbidities, self-reported medication adherence using the eight-item Morisky medication adherence scale (MMAS-8), perceived social support using the Multidimensional Scale of Perceived Social Support (MSPSS) and the current VL result.

The MMAS- 8 is a valid and reliable tool to assess selfreported medication adherence. ${ }^{13}$ The tool contains eight questions, the first seven with yes or no reply (score of 1 for yes and 0 for no) and the last question with a five-point scale (dichotomised into score of 0 for never or rarely and 1 for once in a while, sometimes, usually, or all the time). Thus, the MMAS-8 score ranges from zero to eight. High adherence was classified as score of 0 (responding in affirmative to all indicators of adherence), moderate adherence as score of 1 or 2 and poor adherence as score of greater than 2 .

The MSPSS is also a well-validated and reliable tool for assessing perceived social support. ${ }^{14}$ The MSPSS contains 
12 questions (participants were asked to indicate how they feel about each statement), assessing the perceived support from family (e.g. : 'My family really tries to help me'), friends (e.g.: 'I can count on my friends when things go wrong') and significant other (e.g.: 'There is a special person who is around when I am in need'). Each question has seven possible replies (very strongly disagree, strongly disagree, mildly disagree, neutral, mildly agree, strongly agree and very strongly agree, from one to seven consecutively). The perceived social support was classified into a mean score of 1 to 2.9 as poor support, a score of 3 to 5 as moderate support and a score of 5.1 to 7 as good support.

The recent (less than 1 year old) VL status of each participant was also collected. Based on the national department of health guidelines and WHO recommendations, patient's VL should be monitored at 6 and 12 months upon initiation of HAART and then annually.,15 Treatment failure (virological failure) is defined by a persistently detectable VL of $>1000$ copies $/ \mathrm{mL}$ after at least 6 months of using HAART., ${ }^{3,15}$ For the purposes of this study, VL of $\leq 1000$ copies $/ \mathrm{mL}$ were classified as suppressed and VL of $>1000$ copies / mL as unsuppressed VL.

VL testing was performed by the South African National Health Laboratory Services (NHLS) and was quantified using the automated cobas ${ }^{\circledR}$ 6800/8800 Systems (Roche Molecular Diagnostics, Pleasonton, CA, USA), which is an in vitro nucleic acid amplification test for the quantitation of HIV type 1 (HIV-1) in EDTA plasma of HIV-1-infected individuals. The test can quantitate VL (HIV-1 ribonucleic acid [RNA]) over the range of 20-10 000000 copies /mL.

The questionnaire was directly administered and completed with help of a trained research assistant when translation was needed. Data collection and entry were double-checked thoroughly to ensure avoiding measurement errors.

\section{Data analysis}

Initial analysis included mean, minimum, maximum and the standard deviation given for age. The frequency counts and percentages were performed to describe the demographic characteristics of the participants.

To determine an association between categorical variables of interest and VL, a Pearson's Chi-squared test or a Fisher's exact test was undertaken where a $p \leq 0.05$ suggests a statistically significant association.

Multivariable logistic regression was also performed to evaluate the factors that may predict the viral suppression. Factors which were found to have significant $(p<0.25)$ association with VL were included in the multivariable logistic regression analysis. All analysis was carried out using STATA ${ }^{\circledR} 15$ (Stata Corporation, College Station, Texas, USA) and was evaluated at 5\% level.

A sample size of 375 was required to achieve the objectives of the study, with 95\% confidence level and 5\% margin of error.

\section{Ethical consideration}

Approval was sought from the hospital's CEO and also University of Pretoria's Faculty of Health Sciences ethics committee, reference number: 415/2018. A written informed consent was obtained from each participant and confidentiality was also adhered to as the information given was only used for this study purpose. The participants were identified only by a code number.

\section{Results}

A total of 380 eligible participants from Witbank hospital and surrounding primary healthcare clinics consented and were included in the study. Table 1 illustrates the frequencies and percentages of the demographic and categorical variables.

TABLE 1: Frequencies and percentages of demographic and categorical variables.

\begin{tabular}{|c|c|c|}
\hline Variable & Frequency $(n=380)$ & Percentage (\%) \\
\hline \multicolumn{3}{|l|}{ Age } \\
\hline Mean (s.d.) & $40.48(10.27)$ & \\
\hline $18-29$ & 51 & 13.42 \\
\hline 30-39 & 146 & 38.42 \\
\hline $40-49$ & 117 & 30.79 \\
\hline$\geq 50$ & 66 & 17.37 \\
\hline \multicolumn{3}{|l|}{ Gender } \\
\hline Male & 103 & 27.11 \\
\hline Female & 277 & 72.89 \\
\hline \multicolumn{3}{|l|}{ Education } \\
\hline No school & 17 & 4.47 \\
\hline Elementary & 45 & 11.84 \\
\hline High school & 269 & 70.79 \\
\hline College/university & 49 & 12.89 \\
\hline \multicolumn{3}{|l|}{ Employment } \\
\hline Employed & 154 & 40.53 \\
\hline Unemployed & 215 & 56.58 \\
\hline Retired & 11 & 2.89 \\
\hline \multicolumn{3}{|l|}{ Marital status } \\
\hline Married & 102 & 26.84 \\
\hline Single & 239 & 62.89 \\
\hline Divorced & 7 & 1.84 \\
\hline Widow/widower & 32 & 8.42 \\
\hline \multicolumn{3}{|c|}{ Other medical condition } \\
\hline No & 303 & 79.74 \\
\hline Yest & 77 & 20.26 \\
\hline \multicolumn{3}{|l|}{ Adherence } \\
\hline High & 187 & 49.21 \\
\hline Moderate & 134 & 35.26 \\
\hline Poor & 59 & 15.53 \\
\hline \multicolumn{3}{|c|}{ Perceived social support } \\
\hline Good & 179 & 47.11 \\
\hline Moderate & 180 & 47.39 \\
\hline Poor & 21 & 5.53 \\
\hline \multicolumn{3}{|l|}{ Latest VL } \\
\hline Suppressed $\ddagger$ & 329 & 86.58 \\
\hline Unsuppressed§ & 51 & 13.42 \\
\hline
\end{tabular}

$\dagger$, Includes hypertension (17.1\%), diabetes mellitus (3.2\%), tuberculosis (1.3\%), epilepsy $(1.1 \%)$, asthma $(0.79 \%)$, rheumatoid arthritis $(0.26 \%)$, depression $(0.26 \%)$, eczema $(0.26 \%)$ and deep vein thrombosis $(0.26 \%)$. Of note, $4.2 \%$ had two or more other medical conditions. $\ddagger, \mathrm{VL} \leq 1000$ RNA copies/mL.

$\S, \mathrm{VL}>1000$ RNA copies $/ \mathrm{mL}$

$\mathrm{VL}$, viral load; s.d., standard deviation. 
TABLE 2: Association between categorical variables and viral load.

\begin{tabular}{|c|c|c|c|c|c|}
\hline \multirow[t]{3}{*}{ Variables } & \multicolumn{4}{|c|}{ VL } & \multirow[t]{3}{*}{$p$} \\
\hline & \multicolumn{2}{|c|}{ Suppressed $(n=329)$} & \multicolumn{2}{|c|}{ Unsuppressed $(n=51)$} & \\
\hline & $n$ & $\%$ & $n$ & $\%$ & \\
\hline Age & & & & & 0.303 \\
\hline 18-29 & 41 & 12.46 & 10 & 19.61 & - \\
\hline $30-39$ & 126 & 38.30 & 20 & 39.22 & - \\
\hline $40-49$ & 101 & 30.70 & 16 & 31.37 & - \\
\hline$\geq 50$ & 61 & 18.54 & 5 & 9.8 & - \\
\hline Gender & & & & & 0.157 \\
\hline Male & 85 & 25.84 & 18 & 35.29 & - \\
\hline Female & 244 & 74.16 & 33 & 64.71 & - \\
\hline Education & & & & & 0.505 \\
\hline No school & 15 & 4.56 & 2 & 3.92 & - \\
\hline Elementary & 40 & 12.16 & 5 & 9.8 & - \\
\hline High school & 235 & 71.43 & 34 & 66.67 & - \\
\hline College/university & 39 & 11.85 & 10 & 19.61 & - \\
\hline Employment & & & & & 0.770 \\
\hline Employed & 133 & 40.43 & 21 & 41.18 & - \\
\hline Unemployed & 187 & 56.84 & 28 & 54.9 & - \\
\hline Retired & 9 & 2.74 & 2 & 3.92 & - \\
\hline Marital status & & & & & 0.485 \\
\hline Married & 92 & 27.96 & 10 & 19.61 & - \\
\hline Single & 203 & 61.7 & 36 & 70.59 & - \\
\hline Divorced & 7 & 2.13 & 0 & 0 & - \\
\hline Widow/widower & 27 & 8.21 & 5 & 9.8 & - \\
\hline Other medical conditions & & & & & 0.900 \\
\hline No & 262 & 79.64 & 41 & 80.39 & - \\
\hline Yes & 67 & 20.36 & 10 & 19.61 & - \\
\hline Adherence & & & & & $<0.001$ \\
\hline High & 173 & 52.58 & 14 & 27.45 & - \\
\hline Moderate & 115 & 34.95 & 19 & 37.25 & - \\
\hline Poor & 41 & 12.46 & 18 & 35.29 & - \\
\hline Perceived social support & & & & & 0.017 \\
\hline Good & 164 & 49.85 & 15 & 29.41 & - \\
\hline Moderate & 148 & 44.98 & 32 & 62.75 & - \\
\hline Poor & 17 & 5.17 & 4 & 7.84 & - \\
\hline
\end{tabular}

VL, viral load.

As shown in Table 1, the mean age of the participants was 40.48 years (s.d. 10.27) and the majority were females (72.89\%). In terms of educational level, $83.68 \%$ of the participants were either high school $(70.79 \%)$ or college/university (12.89\%) educated. Only $40.53 \%$ of them were employed; the remaining $59.47 \%$ were either unemployed $(56.6 \%)$ or retired $(2.9 \%)$. With regard to their marital status, most of the participants were single $(62.89 \%)$, the married were $26.84 \%$ and the remaining were either widow/widower $(8.42 \%)$ or divorced (1.84\%).

The majority of the participants did not have additional medical condition $(79.7 \%)$. With regard to self-reported adherence to HAART, $84.47 \%$ of the participants were adherent, but $35.26 \%$ were moderately adherent and $49.21 \%$ were highly adherent. The great majority of the participants $(94.50 \%)$ had social support, of which $47.39 \%$ had moderate perceived social support and $47.11 \%$ had good perceived social support. Regarding VL status, $86.58 \%$ of the participants were virally suppressed (Table 1).
TABLE 3: Factors associated with suppressed viral load using multivariable logistic regression model.

\begin{tabular}{lccc}
\hline Factors & OR & $\mathbf{9 5 \% ~ C l}$ & $p$ \\
\hline Gender & 1 & - & - \\
Male & 1.9 & $0.98-3.76$ & 0.057 \\
Female & & & \\
Adherence & 1 & - & - \\
Poor & 2.8 & $1.32-5.98$ & 0.007 \\
Moderate & 5.3 & $2.41-11.81$ & $<0.001$ \\
High & & & \\
Social support & 1 & - & - \\
Poor & 1.1 & $0.32-3.61$ & 0.901 \\
Moderate & 2.6 & $0.73-9.35$ & 0.141 \\
Good & & & \\
\hline
\end{tabular}

$\mathrm{OR}$, odds ratio; $\mathrm{Cl}$, confidence interval.

Table 2 illustrates the association between demographic variables and VL. The demographic factors, namely, age, gender, educational level, employment status and marital status, were all not associated with VL.

Of the 329 virally suppressed participants, 52.58\% were highly adherent to HAART, and $49.85 \%$ had good social support (Table 2). In the unsuppressed group, 37.25\% had moderate adherence followed by poor adherence (35.29\%), and $62.75 \%$ had moderate social support. There was a statistically significant association between adherence and VL $(p<0.001)$ and between social support and VL $(p=0.017)$ (Table 2).

Table 3 presents the factors associated with suppressed VL using multivariable logistic regression. All variables with $p<0.25$ using the Fisher's exact test were included in the model. Only adherence was found to be statistically significantly associated with suppressed VL. Moderately and highly adherent participants were 2.8 and 5.3 times more likely to have a suppressed VL when compared to poorly adherent participants.

\section{Discussion}

The relationship between different forms of social support and VL is inconclusive. Our results show that, in a bivariate analysis, perceived social support is significantly associated with VL; however, a multivariable analysis shows that perceived social support is not independently associated with viral suppression. Cunha et al. in Brazil, assessing the effect of social support on quality of life, CD4 and VL, found that those with a satisfactory social support had significant reduction in VL. ${ }^{6}$ Randomised control trials done by Cuong et al. ${ }^{8}$ in Vietnam and Nachega et al. ${ }^{9}$ in SA, assessing impact of peer support on virologic outcome, have both found no association between intervention and control group; whilst another RCT done by Kenya et al., assessing impact of CHW on clinical outcome (CD4 and VL), found that intervention group had significant lower VL than control.?

A meta-analysis and systematic review by Hart et al., assessing the effect of DOT-HAART on VL, CD4 and adherence, found DOT-HAART had a significant effect on 
VL, CD4 and adherence compared to the control group. ${ }^{10}$ However, when analysis was done to RCTs only, DOTHAART had no significant effect on VL. In contrast, another systematic review and meta-analysis by Chishinga et al., assessing the effect of home-based interventions on VL in adults on HAART in Africa, found insufficient data to say there is a difference in viral suppression at 12 months in the home-based group compared to the standard care group. ${ }^{11}$

It is important to point out that the aforementioned studies used different methodology, support assessment tools and form of support. When assessing the association between perceived social support and depression in HIV patients, Sule et al. in Nigeria used similar methodology and the same social support tool and found no association between perceived social support and VL. ${ }^{16}$ However, their study was not primarily designed to assess this association.

The mean age of the participants was 40.5 years (s.d. $=10.3$ ). Age was not associated with viral suppression, in keeping with findings of a study done in Ga-Rankuwa, SA, by Mogosetsi et al. ${ }^{17}$ However, some studies have shown that younger age of less than 35 years was associated with unsuppressed VL, ${ }^{18,19}$ whilst older age was more likely to achieve suppressed VL. ${ }^{20,21}$ In our study, females were in the majority (72.9\%). This finding is similar to the local and regional literatures. ${ }^{9,17,21,22,23}$ The finding may be explained in two ways: the adult HIV prevalence in females is much higher than in males in SA $(26.3 \%$ vs. $14.8 \%)$ as reported in the fifth SA national HIV prevalence, incidence, behaviour and communication survey; ${ }^{2}$ in addition, more women than men living with HIV are engaged in care in SA (60\% vs. $43 \%)$ as reported by Bor et al. ${ }^{4}$ The association between gender and viral suppression is equivocal. This study has found no association between gender and viral suppression; this concurs with some studies. ${ }^{17,24}$ However, other studies have shown that male gender was associated with unsuppressed ${ }^{18,22}$ and suppressed VL; ;0 whilst yet in other studies, female gender was associated with unsuppressed VL. ${ }^{19,21}$

The study found that a huge number of the participants $(83.7 \%)$ were at least high school educated. Nonetheless, educational level was not associated with viral suppression. This finding concurs with studies done in $\mathrm{SA}^{17} \mathrm{Spain}^{25}$ and Uganda. ${ }^{26}$ In contrast, other studies have shown lower educational level to be associated with unsuppressed VL. ${ }^{19,27,28}$ Most of the participants were unemployed. This finding reflected what has been reported by the authorities in SA. There was high unemployment rate of between $26.7 \%$ and $27.6 \%$ from the first quarter of 2018 to the first quarter of 2019 in SA. ${ }^{29}$ Employment status was also not associated with viral suppression, in agreement with the studies done in $\mathrm{SA}^{, 17} \mathrm{US}^{19}$ and Uganda. ${ }^{26}$ In terms of marital status, the majority of our participants were single and there was no association with viral suppression. Studies in SA by Mogosetsi et al. ${ }^{17}$ and in Uganda by Kazooba et al. ${ }^{26}$ have also found that marital status was not associated with viral suppression. However, in the multinational HIV Prevention
Trials Network, Eshleman et al. reported that being married was associated with unsuppressed VL, although the association was weak $(p<0.04) .^{28}$

The majority $(80 \%)$ of our participants did not have additional medical conditions. Of those who had additional medical conditions, hypertension was the most comorbid condition. Additional medical conditions (comorbidity) were not associated with viral suppression. This finding is consistent with a recent study done in Khayelitsha, SA, by George et al., who assessed the association between noncommunicable diseases (NCDs) and detectable VL and found no association between them. ${ }^{21}$ It is important to note that George et al. defined detectable VL as $>40$ copies $/ \mathrm{mL}$, unlike in our study where unsuppressed VL is defined as $>1000$ copies $/ \mathrm{mL}$.

The UNAIDS had set a global target of 90-90-90 to curb the HIV epidemic by the year 2020. By mid-2015, Mpumalanga Province (where our study population resides) had achieved 84-58-70.30 Our study had shown a viral suppression rate of $86.6 \%$, which was well on track to achieve the last 90 (90\% of patients on HAART to have suppressed VL) target by the year 2020. In order to achieve and maintain viral suppression, high levels of adherence to HAART is essential. A decline in the level of adherence to between $70 \%$ and $89 \%$ has been shown to be associated not only with viral rebound (unsuppressed VL) but also with resistance to HAART. ${ }^{31}$ Our data have shown that the higher the adherence level, the more likely the VL is suppressed. This finding is supported by multiple studies in different parts of the world. ${ }^{18,19,24,32,33,34}$ The finding may not be surprising. As one would expect, if the medication was not taken or taken erratically, it would not have the desired effect on the virus.

\section{Limitations}

Besides the inherent limitations of a cross-sectional study, the study assessed participants who presented to the clinics only, patients who defaulted HAART for a longer period or who were too sick to attend the clinics may have been missed. Trained assistants (nurses) helped with translation when needed; therefore, participants may have responded to questions in a socially acceptable manner instead of responding frankly. Moreover, because of the reliance on self-reporting, response bias needs to be taken into consideration. Despite these limitations, the authors believe the findings of the study have some relevance in discussions regarding the association between social support and VL amongst adults on HAART.

\section{Conclusion and recommendations}

The study has found that the vast majority (94.5\%) of the participants had moderate $(47.4 \%)$ to good $(47.1 \%)$ perceived social support. The majority of the participants also had moderate (35.3\%) to high (49.2\%) self-reported adherence. In this study, the viral suppression rate was high $(86.6 \%)$. 
Although the study has found that there was significant association between perceived social support and viral suppression, good social support did not predict viral suppression. Self-reported adherence to HAART was significantly associated with VL and was highly predictive of viral suppression.

The study has highlighted the importance of adherence to HAART, as self-reported adherence was highly predictive of viral suppression. Therefore, assessing and addressing adherence issues at every contact with patients taking HAART is highly recommended in order to minimise treatment failures. Good perceived social support did not predict viral suppression in this study. However, as the perception of social support may change over time, a prospective cohort study is needed to assess the change in perception of social support and its effect on VL.

\section{Acknowledgements}

The authors would like to thank Edwin Mashego (Wellness clinic, Witbank Hospital) for his assistance in the data collection process, Tshifhiwa Nkwenika (Biostatistics Research Unit, South African Medical Research Council) for her assistance in the data analysis and the patients who participated in the study.

\section{Competing interests}

The authors declare that they have no financial or personal relationships that may have inappropriately influenced them in writing this article.

\section{Authors' contributions}

T.M.H., researcher seeking the MMed (FamMed) degree at University of Pretoria; C.B., research supervisor; L.N., research co-supervisor and corresponding author.

\section{Funding information}

The authors received no financial support for the research, authorship and/or publication of this article.

\section{Data availability statement}

Data sharing is not applicable to this article, as no new data were created or analysed in this study.

\section{Disclaimer}

The views expressed in this article are the authors' own and are not an official position of the University of Pretoria.

\section{References}

1. Joint United Nations Programme on HIV/AIDS. UNAIDS data. Geneva: UNAIDS; 2019.

2. Human Sciences Research Council (HSRC). The fifth South African national HIV prevalence, incidence, behaviour and communication survey, 2017: HIV impact assessment summary report. Cape Town: HSRC Press; 2018.
3. World Health Organization. Consolidated guidelines on the use of antiretroviral drugs for treating and preventing HIV infection: Recommendations for a public health approach. 2nd ed. Geneva: World Health Organization; 2016.

4. Bor J, Brennan A, Carmona S, et al. Towards 90-90-90: How close is South Africa to reaching the UNAIDS HIV treatment targets? Johannesburg: HE2RO-NHLS Policy Brief; 2016.

5. Burgoyne RW. Exploring direction of causation between social support and clinical outcome for HIV-positive adults in the context of highly active antiretroviral therapy. AIDS Care. 2005;17(1):111-124. https://doi.org/10.1080/095401204123 31305179

6. Cunha GH, Galvão MT, Fiuza ML, et al. Effect of social support on quality of life, CD4+ T-cell count and viral load of people living with HIV/AIDS. Int Arch Med. 2016;9. https://doi.org/10.3823/2082

7. Kenya $S$, Jones J, Arheart $\mathrm{K}$, et al. Using community health workers to improve clinical outcomes among people living with HIV: A randomized controlled trial. AIDS Behav. 2013;17(9):2927-2934. https://doi.org/10.1007/s10461-013-0440-1

8. Cuong DD, Sönnerborg A, Van Tam V, et al. Impact of peer support on virologic failure in HIV-infected patients on antiretroviral therapy - A cluster randomized
controlled trial in Vietnam. BMC Infect Dis. 2016;16(1):759. https://doi. org/10.1186/s12879-016-2017-x

9. Nachega JB, Chaisson RE, Goliath R, et al. Randomized controlled trial of trained patient-nominated treatment supporters providing partial directly observed antiretroviral therapy. AIDS. 2010;24(9):1273-1280. https://doi.org/10.1097\%2F QAD.0b013e328339e20e

10. Hart JE, Jeon CY, Ivers LC, et al. Effect of directly observed therapy for highly active antiretroviral therapy on virologic, immunologic, and adherence outcomes: A meta-analysis and systematic review. J Acquir Immune Defic Syndr 2010;54(2):167-179. https://doi.org/10.1097/QAl.0b013e3181d9a330

11. Chishinga N, Godfrey-Faussett P, Fielding K, Ayles H. Effect of home-based interventions on virologic outcomes in adults receiving antiretroviral therapy in Africa: A meta-analysis. BMC Public Health. 2014;14(1):239. https://doi. org/10.1186/1471-2458-14-239

12. Streeter CL, Franklin C. Defining and measuring social support: Guidelines for social work practitioners. Res Soc Work Pract. 1992;2(1):81-98. https://doi. org/10.1177/104973159200200107

13. Morisky DE, Ang A, Krousel-Wood M, Ward HJ. Predictive validity of a medication adherence measure in an outpatient setting. J Clin Hypertens. 2008;10(5):348-354. https://doi.org/10.1111/j.1751-7176.2008.07572.x

14. Zimet GD, Dahlem NW, Zimet SG, Farley GK. The multidimensional scale of perceived social support. J Pers Assess. 1988;52(1):30-41. https://doi. org/10.1207/s15327752jpa5201_2

15. Department of Health, Republic of South Africa. National consolidated guidelines for the prevention of mother-to-child transmission of HIV (PMTCT) and the management of HIV in children, adolescents, and adults. Pretoria: Department of Health; 2014.

16. Sule HM, Gyang MD, Agbir MT, Okonoda KM. Perceived social support and its association with depression among patients infected with HIV: A hospital based study in Jos, Nigeria. Int J HIV/AIDS Prev Educ Behav Sci. 2019;5(1):68-75. https:// doi.org/10.11648/j.ijhpebs.20190501.19

17. Mogosetsi NJ, Mabuza LH, Ogunbanjo GA. The prevalence of HIV load suppression and related factors among patients on ART at Phedisong 4 clinic, Pretoria, South Africa. Open Public Health J. 2018;11(1):135-146. https://doi.org/10 2174/1874944501811010135

18. Bulage L, Ssewanyana I, Nankabirwa V, et al. Factors associated with virologica non-suppression among HIV-positive patients on antiretroviral therapy in Uganda, August 2014-July 2015. BMC Infect Dis. 2017;17(1):326. https://doi.org/10.1186/ s12879-017-2428-3

19. Shacham E, Nurutdinova D, Onen N, Stamm K, Overton ET. The interplay of sociodemographic factors on virologic suppression among a US outpatient HIV clinic population. AIDS Patient Care STDS. 2010;24(4):229-235. https://doi. org/10.1089/apc.2009.0275

20. Cescon AM, Cooper C, Chan K, et al. Factors associated with virological suppression among HIV-positive individuals on highly active antiretroviral therapy in a multi-
site Canadian cohort. HIV Med. 2011;12(6):352-360. https://doi.org/10.1111/ site Canadian cohort. HIV
j.1468-1293.2010.00890.x

21. George S, McGrath N, Oni T. The association between a detectable HIV viral load and non-communicable diseases comorbidity in HIV positive adults on antiretroviral therapy in Western Cape, South Africa. BMC Infect Dis. 2019;19(1):348. https://doi.org/10.1186/s12879-019-3956-9

22. Joseph Davey D, Abrahams Z, Feinberg M, et al. Factors associated with recent unsuppressed viral load in HIV-1-infected patients in care on first-line antiretroviral therapy in South Africa. Int J STD AIDS. 2018;29(6):603-610. https://doi. org/10.1177/0956462417748859

23. Muula AS, Ngulube TJ, Siziya S, et al. Gender distribution of adult patients on highly active antiretroviral therapy (HAART) in Southern Africa: A systematic review. BMC Public Health. 2007;7(1):63. https://doi.org/10.1186/1471-2458-7-63

24. Rangarajan S, Colby DJ, Le Truong G, et al. Factors associated with HIV viral load suppression on antiretroviral therapy in Vietnam. J Virus Erad. 2016;2(2):94-101. https://doi.org/10.1016/S2055-6640(20)30466-0

25. Collazos J, Asensi V, Carton JA, Ibarra S. The influence of the patients' educational levels on socioeconomic, clinical, immunological and virological end-points. AIDS Care. 2009;21(4):511-519. https://doi.org/10.1080/09540120802270300

26. Kazooba P, Mayanja BN, Levin J, Masiira B, Kaleebu P. Virological failure on firstline antiretroviral therapy; associated factors and a pragmatic approach for switching to second line therapy-evidence from a prospective cohort study in switching to second line therapy-evidence from a prospective cohort study in
rural South-Western Uganda, 2004-2011. Pan Afr Med J. 2018;29(1):1-6. https:// doi.org/10.11604/pamj.2018.29.191.11940 
27. Del Amo J, Lodi S, Dray-Spira R, et al. Inequalities by educational level in response to combination antiretroviral treatment and survival in HIV-positive men and
women in Europe. AIDS. 2017;31(2):253-262. https://doi.org/10.1097/QAD. 0000000000001270

28. Eshleman SH, Wilson EA, Zhang XC, et al. Virologic outcomes in early antiretroviral treatment: HPTN 052. HIV Clin Trials. 2017;18(3):100-109. https://doi.org/10.108 0/15284336.2017.1311056

29. Statistics South Africa. Quarterly labour force survey, Quarter 1, 2019. Pretoria: Stats SA; 2019. Statistical release P0211.

30. Johnson LF, Dorrington RE, Moolla H. Progress towards the 2020 targets for HIV diagnosis and antiretroviral treatment in South Africa. S Afr J HIV Med. 2017;18(1):1-8. https://doi.org/10.4102/sajhivmed.v18i1.694
31. Sethi AK, Celentano DD, Gange SJ, Moore RD, Gallant JE. Association between adherence to antiretroviral therapy and human immunodeficiency virus drug
resistance. Clin InfectDis. 2003;37(8):1112-1118. https://doi.org/10.1086/378301

32. Ehlers VJ, Tshisuyi ET. Adherence to antiretroviral treatment by adults in a rural area of Botswana. Curationis. 2015;38(1):1-8. https://doi.org/10.4102/curationis.v38i1.1255

33. Arnsten JH, Demas PA, Farzadegan $\mathrm{H}$, et al. Antiretroviral therapy adherence and viral suppression in HIV-infected drug users: Comparison of self-report and electronic monitoring. Clin Infect Dis. 2001;33(8):1417-1423. https://doi.org/ $10.1086 / 323201$

34. Shah B, Walshe L, Saple DG, et al. Adherence to antiretroviral therapy and virologic suppression among HIV-infected persons receiving care in private clinics in Mumbai, India. Clin Infect Dis. 2007;44(9):1235-1244. https://doi.org/10.1086/513429 